\section{Hybrid visual representation \\ process in the teaching of product design: analog and digital}

\section{Vanderlei Prado ${ }^{\mathrm{a}}$ Milton Sogabe ${ }^{b}$}

Universidade Anhembi Morumbi

\section{This article presents an investigation of the processes of visual} representation in product design, with special attention to the hybridism between the processes of analogical representations and the processes of digital representations in the teaching of design. In order to analyze and understand relevant aspects of hybridism between analog and digital, a study is also relevant to verify the applicability of this hybridity not only in the methodological context of teaching product design, but also in the contemporary context of professional practice for development of products.

To contextualize the state of the art regarding the processes of visual representation in the field of product design, the study begins by presenting a brief bibliographic survey to identify and later classify the processes of visual representation in two categories: analog and digital. Subsequently, a practical experiment applied through a workshop on some phases of product development will be presented, alternating between the process of analog representation and the process of digital representation, with a focus on hybridism between both. Finally, an analysis of the results and possibilities achieved in the product development phases is presented, taking into account that specifically in the field of product design, the final goal of each phase of the process is to obtain a visual result.

The study brings reflections about that the process of making drawings in the design activity has been changing over time, as well as the quality necessary for the presentation of the development phases. At first, it is possible to verify that the advent of computer graphics software restricted hand-on-paper sketches on paper to the creative phase at the beginning of the design process, however with the establishment of the use of digital tools and other technological devices in product design, the respective advantages and disadvantages are clearer, and it is time to re-evaluate the applicability of analog and digital processes from the pedagogical point of view in teaching design, as well as from the point of view of the quality of design solutions in the professional practice of industrial designers. The disciplined search for hybridity through the navigability between analog and digital representation processes, may prove to be a strategy to promote the integration of design teams, in addition to promoting better communication by reducing the interpretative ambiguities of other departments in areas involved in the projects, enabling due importance for a broader creative process and supported by design methods.

KEYWORDS

Analog Representation Process, Digital Representation Process, Education, Hybridism and Product Design 